\title{
Early skin-to-skin contact in a child friendly hospital: perceptions of the obstetric nurses
}

\author{
Contato pele a pele precoce em um hospital amigo da \\ criança: percepções das enfermeiras obstétricas \\ Contacto piel a piel temprano en un hospital amigo del niño: \\ percepciones de las enfermeras obstetrices

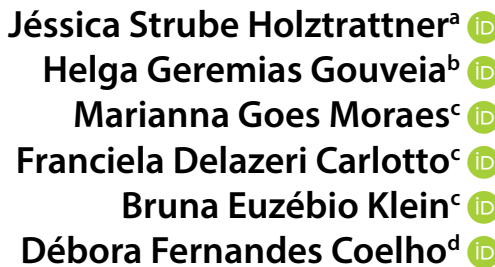

How to cite this article:

Holztrattner JS, Gouveia HG, Moraes

MG, Carlotto FD, Klein BE, Coelho DF.

Early skin-to-skin contact in a child

friendly hospital: perceptions of the

obstetric nurses. Rev Gaúcha Enferm.

2021;42:e20190474. doi: https://doi

org/10.1590/1983-1447.2021.20190474
Universidade Federal de Ciências da Saúde de Porto Alegre (UFCSPA). Porto Alegre, Rio Grande do Sul, Brasil.

b Universidade Federal do Rio Grande do Sul (UFRGS), Escola de Enfermagem, Departamento de Enfermagem Materno-Infantil. Porto Alegre, Rio Grande do Sul, Brasil.

Universidade Federal do Rio Grande do Sul (UFRGS). Porto Alegre, Rio Grande do Sul, Brasil.

d Universidade Federal de Ciências da Saúde de Porto Alegre (UFCSPA), Departamento de Enfermagem. Porto Alegre, Rio Grande do Sul, Brasil.

\section{ABSTRACT}

Objective: To know the nurses' perception about early skin-to-skin contact.

Methods: A qualitative and exploratory-descriptive study carried out at the Obstetric Center of a university hospital in southern Brazil. The participants were eight nurses who answered a qualitative interview in April 2019. The interviews followed a guiding script and were analyzed according to thematic content analysis: data sorting and classification and final analysis.

Results: Nurses know the skin-to-skin contact practice and the importance of doing it properly. In their work routine, they perceive that this contact does not happen as it should and they understand the importance of recording it.

Conclusion: Nurses aim for skin-to-skin contact to be carried out in an early and uninterrupted manner; however, the limitations related to the health team's work processes are highlighted. The study reinforces the importance of reducing unnecessary interventions at birth.

Keywords: Nurse midwives. Breastfeeding. Delivery rooms. Mother-child relations. Infant, newborn.

\section{RESUMO}

Objetivo: Conhecer percepções de enfermeiras sobre o contato pele a pele precoce.

Método: Estudo qualitativo, exploratório-descritivo, realizado no Centro Obstétrico de um hospital universitário do sul do Brasil. As participantes foram oito enfermeiras, as quais responderam a uma entrevista qualitativa em abril de 2019. As entrevistas seguiram um roteiro norteador e foram analisadas conforme Análise de Conteúdo do tipo temática: ordenação e classificação dos dados e análise final.

Resultados: As enfermeiras conhecem a prática do contato pele a pele e a importância de realizá-la de maneira adequada. Percebem que, em sua rotina de trabalho, este contato não é realizado adequadamente e compreendem a importância de registrar sua realização. Conclusão: As enfermeiras almejam que o contato pele a pele seja realizado da maneira precoce e ininterrupta; contudo, destacamse as limitações relacionadas aos processos de trabalho da equipe de saúde. 0 estudo reforça a importância da redução de intervenções desnecessárias no nascimento.

Palavras-chave: Enfermeiras obstétricas. Aleitamento materno. Salas de parto. Relações mãe-filho. Recém-nascido.

\section{RESUMEN}

Objetivo: Conocer la percepción de las enfermeras sobre el contacto piel a piel temprano.

Método: Estudio cualitativo y exploratorio-descriptivo, realizado en el Centro Obstétrico de un hospital universitario del sur de Brasil. Las participantes fueron ocho enfermeras, quienes respondieron a una entrevista cualitativa en abril de 2019. Las entrevistas siguieron un guión rector y fueron analizadas según Análisis de Contenido del tipo temático: ordenamiento y clasificación de datos y análisis final.

Resultados: Las enfermeras conocen la práctica del contacto piel a piel y la importancia de realizarlo adecuadamente. Se dan cuenta de que, en su rutina de trabajo, este contacto no se realiza correctamente y entienden la importancia de registrarlo.

Conclusión: La enfermera tiene como objetivo que el contacto piel a piel se realice de forma temprana e ininterrumpida; sin embargo, se destacan las limitaciones relacionadas con los procesos de trabajo del equipo de salud. El estudio refuerza la importancia de reducir las intervenciones innecesarias al nacer.

Palabras clave: Enfermeras obstetrices. Lactancia materna. Salas de parto. Relaciones madre-hijo. Recién nacido. 


\section{口INTRODUCTION}

The theme of the humanization of delivery and birth is very present in the current scenario. Governmental initiatives highlight that labor is a physiological process that occurs without complications for most women and newborns and that it should occur in a biological, spiritual and psychologically safe environment for the family, with care centered on the woman, based on scientific evidence and human rights. However, in recent years, there has been an increase in interventions that should be used only to reduce risks or treat complications, and women started to lose protagonism at this moment ${ }^{(1-2)}$

In the search for best practices in labor and birth, in 2018, the World Health Organization (WHO) launched new global care guidelines, with the intention of reducing unnecessary interventions. The recommendations cover aspects related to the survival of the mother and the newborn, indicating safe practices that provide positive experiences for women and their families ${ }^{(2)}$. In this context, it is recommended that newborns remain in skin-to-skin contact (SSC) with their mothers in the first hour of life, which prevents hypothermia, promotes the establishment of breastfeeding, helps in the adaptation of newborns to extrauterine life, increases blood glucose levels, improves the mother's affection and bonding behavior, and influences longer duration of breastfeeding ${ }^{(2-3)}$.

The newborns' first hour of life is a sensitive period, referred to in the literature as "sacred hour" or "golden hour", where they are calm, with their eyes open and receptive to the external environment, ideal to initiate interaction with their mothers. By being placed in the mother's chest immediately after delivery, the newborn, through reflexes and olfactory stimuli, is able to locate the mother's nipple and initiate the breastfeeding process. These sensory stimuli, such as touch and odor, promote the release of maternal oxytocin, which, in addition to helping prevent bleeding, stimulates the maternal instinct to protect the newborn and contributes to the ejection of colostrum ${ }^{(4-5)}$.

Regarding the benefits of SSC in promoting and maintaining breastfeeding, the $\mathrm{WHO}$ has been promoting efforts to encourage the practice for some time. In the 1990s, the Baby Friendly Hospital Initiative (Iniciativa Hospital Amigo da Criança, IHAC) was conceived, with its guidelines presenting the "Ten Steps to Successful Breastfeeding". In the fourth step, it is recommended that the professional helps to initiate breastfeeding, placing the newborns in SSC with their mothers immediately or within five minutes after delivery, and this contact must be prolonged for at least one hour ${ }^{(6)}$.
However, despite the fact that SSC is a safe and inexpensive procedure with proven benefits in the short and long term for mothers and infants, there is still resistance by the professionals to postpone routine tasks and care in favor of SSC. This practice is not yet fully consolidated in the health services, especially those that maintain a hospital-centered, interventionist and medicalized approach ${ }^{(7)}$.

Professional experience shows certain distance between the scientifically proven benefits for mothers and newborns and the practices effectively developed in the hospital delivery scenario. With regard to SSC, it is observed that there are factors that hinder the understanding that newborns in good clinical conditions must stay with their mothers immediately after delivery for at least an hour, especially when the birth takes place by cesarean section. Factors such as low room temperature, procedures performed on the newborn, electrodes placed on the mother, maternal instability due to anesthesia, lack of space for the child's accommodation on the mother's lap, and lack of collaboration from the professionals are practices that influence humanized care, being observed with some frequency.

Although the hospital routine contributes to the mother-baby separation soon after birth, nurses have been identified as highly influential in the better development of the relationships between parents and infants at this exciting moment of their lives. Some parents report that the information they received from the nurses and their encouragement made them more likely and motivated to practice SSC early after delivery ${ }^{(8)}$.

In addition to what was discussed about the nurses' work in the Obstetric Centers, it is important to record the proper care, especially SSC, valuing the professionals' actions, patient safety and communication in the health team. The nurses' record is the greatest instrument for evaluating the quality of care provided and reflects all the commitment and strength of the Nursing team, in addition to serving as a research, teaching, statistics and planning instrument $t^{(9)}$. Lack of registration of practices or their incomplete performance can influence quality and continuity of care, reflecting on practices that may affect patient safety.

A number of studies on the practice of SSC have shown their results through the analysis of institutional indicators. There are few observational studies and on the professionals' perception with respect to the topic. By understanding the view of those who work directly with childbirth care, it is estimated that the barriers and difficulties of promoting this practice are better identified, which is of great importance for mothers and newborns. Thus, this study aimed to learn the nurses' perceptions about skin-to-skin contact early after delivery. 


\section{METHODS}

A qualitative and exploratory and descriptive study conducted at the Obstetric Center of a university hospital in the south of the country, a public and university institution that is part of the university hospital network belonging to the Ministry of Education and academically linked to the Federal University of Rio Grande do Sul, integrated to the Baby Friendly Hospital Initiative since 1997. The Obstetric Center has Obstetric Emergency, pre-delivery and delivery rooms, as well as cesarean rooms, recovery rooms and immediate care rooms for newborns. The Unit is a reference for the care of pregnant women at risk and high risk in the state of Rio Grande do Sul, serves around 300 monthly deliveries, mostly vaginal, and has three nurses per shift, all of whom are obstetric nurses.

The study participants were eight nurses who work in the birth scenario at the Obstetric Center Unit of the hospital. The nurses' participation took place by means of semi-structured interviews. Thus, to determine the sample number at this stage, it was considered that, in qualitative research studies, sampling must cover the entire problem in its multiple dimensions, and the number of participants interviewed is not relevant but rather the quality of the empirical material resulting from the interviews, until the moment when data saturation is reached ${ }^{(10)}$.

As inclusion criteria, it was established that the nurses should work in the Obstetric Center Unit of the institution and been working for more than six months in such place. As exclusion criteria, it was decided to exclude nurses who were on leave or on vacation at the time of data collection. The participants were drawn by the roster of their work shift so that the sample had at least one representative from each shift.

The nurses who agreed to participate in the research signed a Free and Informed Consent Form, in two identical copies, which contained the research objectives, the time allocated from 15 to 20 minutes to answer the interview, the absence of direct benefits, and the possible future benefits of the research, as well as the possible discomforts resulting from their participation.

Data collection took place in April 2019, by means of a qualitative interview, following a script of guiding questions with open questions to be answered by the participant. The interviews were conducted by three authors (research initiation scholarship students at that time) who were previously trained to standardize data collection, and took place in a private room at the study locus. The interactions were recorded with electronic audio equipment with the participants' consent and later transcribed in full by the researcher to ensure reliability of the information. The names of the interviewees were replaced by the letter " $E$ " followed by a sequential Arabic numerical order, in order to preserve the participants'anonymity. Data was analyzed using the thematic type Content Analysis suggested by Minayo, Deslandes and Gomes ${ }^{(11)}$, which includes three stages: data sorting, data classification and final analysis.

The first stage (data sorting) consisted in the mapping of the data collected, which involved the transcription of recordings, re-reading of the material and organization of the reports. In the second stage (data classification), repeated readings of the texts resulted in questions about the relevant information, which were allocated in thematic categories that determine the information sets. In the final analysis, there was an interrelation between data resulting from the study and the theoretical frameworks found, that is, the relationships between the concrete and the abstract, theory and practice.

This study was prepared and conducted respecting all the ethical principles established by Resolution 466/12 of the National Health Council(12), and was approved by the Research Ethics Committee via Plataforma Brasil (CAAE 94996518.0.0000.5327).

\section{RESULTS AND DISCUSSION}

The interviews were organized and analyzed. After repeated readings, three thematic categories emerged: theoretical-practical knowledge on skin-to-skin contact; the reality of the skin-to-skin contact practice; and Nursing records on skin-to-skin contact.

\section{Theoretical-practical knowledge on skin-to- skin contact}

Regarding knowledge about early SSC after delivery, the nurses' reports pointed out that their knowledge is in accordance with global criteria stipulated by the IHAC, which recommends that newborns must be placed in SSC with the mother immediately or within five minutes after delivery, and that this contact must be prolonged for at least one hour(6):

[...] SSC is the placement of the baby, without any clothes, directly on the mother's skin, on her chest, right? [...] and so it must remain for at least an hour. (E4)

[...] The baby is placed next to the mother's body, without any cloth, clothes, anything. [...] It's immediate contact, and the baby must stay at least one hour, skin to skin, 
without interruption. And then, if the pediatrician needs to do some exam, like physical examination, then everything is on the mother. And placing the baby to suck the mother's breast [...]. (E8)

There was an understanding that SSC must occur uninterruptedly in the first hour of life and that the newborn must stay on the mother's naked lap, in direct contact with the mother's skin. In the E8's speech, it was observed that, in addition to SSC, the interviewee understands that the newborn must be encouraged to suck on the mother's breast in the first hour of life. The authors believe that this continuity of good practices at birth is important, not fragmenting care and focusing it on the needs of women and newborns.

A study carried out in a hospital in the state of Amapá with nurses and nursing technicians showed that $76.7 \%$ of the interviewed professionals knew, agreed and implemented the practice of early SSC after delivery; that, despite knowing, $10 \%$ did not agree with the practice; and that, even though they knew and agreed with its importance, 13.3\% did not stimulate SSC between mothers and newborns due to lack of hospital structure. It was considered that, in the study hospital, there is humanized care and that the bond between mothers and newborns is encouraged ${ }^{(1)}$.

It is important that the health team has knowledge about the practice and benefits of SSC, both for women and newborns. A team aware of the practice tends to facilitate its implementation, increasing its frequency. Training, conversation circles and improvement of the practice of early SSC after delivery are suggested.

In this study, in a conversation about the importance of SSC, the nurses interviewed highlighted mainly the establishment of the "bond" between the mother and the newborn, in addition to the prevention of postpartum hemorrhages, maintenance of temperature and stabilization of the vital signs of the newborn. Terms related to breastfeeding also appeared in the participants'statements:

\section{[...] It improves bonding, it improves breastfeeding, im- printing, everything... (E2)}

[...] it improves the bond issue... and the issue of the woman's clinical aspects, bleeding, it decreases the risk of uterine hypotonia... The baby is calmer, the vital signs stabilize, it warms the baby, it facilitates breastfeeding in the first hour... (E8)

The findings showed that the nurses know the importance of SSC for the physiological adaptation of mothers and newborns after delivery. Furthermore, they pointed out the improvement of maternal emotional issues, improved stabilization of the newborn and positive effects on early breastfeeding.

For the mothers, SSC improves postpartum stress, reduces uterine bleeding, reduces the time of placental expulsion and helps in breastfeeding initiation. This contact induces an increase in the production of oxytocin, improving the maternal social response capacity, which may promote an increase in parental behavior and attachment ${ }^{(13)}$.

The positive effects of SSC for newborns regarding the practice of breastfeeding in the immediate postpartum period are linked to the establishment of breastfeeding and can extend to late childhood. Cardiorespiratory stabilization and temperature maintenance, essential components for the prevention of neonatal morbidity, are promoted by SCC in an economical, safe and effective manner ${ }^{(3)}$.

Participants of another study, working at the Obstetric Center of a hospital in the state of Rio Grande do Sul (RS), showed that they recognized SSC as an event that provides significant feelings for the mothers and for those who accompany them. The professionals understand that this practice enables the bond between mothers and newborns, the enchantment and the discovery of the idealized child, in addition to being a source of encouragement to newborns, generating interaction between both ${ }^{(7)}$.

These feelings were also observed in the nurses' statements, who emphasized the importance of the first interaction between mothers and newborns provided by early SSC after delivery:

\section{[...] there, it [NB] will feel safe, it will feel protected... (E1) \\ [...] it's like a reward for her. Receiving the baby in her arms and sharing this affection, like that, human warmth, the touch, the look, all of that at that moment... (E6) \\ [...] it's a moment when everything stops, the mother calms down, the baby calms down... I think it is through interaction, affection, love, that this happens... (E7)}

SSC after delivery is an important stimulus to start creating affective bonds between mothers and newborns. At this point, the newborn calms down and tunes in to the mother, crying and stress are reduced, and the maternal anxiety caused by separation from the child decreases. The woman will feel, touch and hold the newborn, favoring the strengthening of the bond ${ }^{(1)}$.

The nurses also showed that they believe in a paradigm shift with respect to the care of the NB immediately after delivery. They noticed advances in the practice of SSC over the years they have worked at the Obstetric Center and 
hope that the care practices in the hospital environment will evolve in order to reduce interventions and distancing between mothers and newborns:

\section{[...] I think that skin-to-skin came to help this emotional, affective part of the family a lot, that we didn't have before [...] I think it will take manyyears for people to realize that the baby is not ours, the baby belongs to the mother and the father. We weren't even supposed to touch it. (E7) \\ $[. .$.$] it's a change of process, of learning [...] But I believe$ that this is still going to change, it's heading towards that... Well, it's already way better. (E8)}

However, the nurses believe that performing SSC as recommended by the $\mathrm{HAC}$ will occur in the medium/long term. A process change in the birth scenario is imperative to reduce the discrepancy between routine practice and the most current scientific evidence ${ }^{(2)}$.

\section{The reality of the skin-to-skin contact practice}

Regarding the practice of SSC, it was verified in the nurses' reports that, despite the knowledge and the importance of this contact, the reality of care does not represent, in all cases, the proposals recommended by the IHAC ${ }^{(6)}$. The nurses understand that, in their work routine, this contact between mothers and newborns exists, but it does not occur properly, since pediatricians remove the newborns from the mothers'lap and provide the first care in a heated crib, where the babies stay for more than five minutes in some cases:

\section{[...] in good conditions, the babies are born and stay on their mothers' lap, depending on the pediatrician who is there. And then, afterwards, they go to the warm crib, the first exams are made with the pediatrician, they are weighed and returned to the mothers. (E3) \\ [...] But this contact is not as it should be, to spend one hour without any intervention. (E4) \\ [...] This first baby care, which is the physical examination and identification of the baby, is done in the heated crib [...] So this skin-to-skin is not reliable, because it's broken. (E8)}

Possible institutional difficulties to enable SSC as recommended were highlighted in the nurses'reports. The hospital routine interferes with the fulfillment of the IHAC recommendations, and the newborns are separated from their mothers at birth, even without significant clinical reasons, delaying bonding with the mothers. This care routine makes health care impersonal, valuing neither the women's/newborns'individuality nor the care that goes beyond the biological aspect.

A research study carried out at a university hospital in the United States not accredited as a Baby Friendly Hospital showed that physicians and nurses who worked in the obstetric center pointed out hospital practices similar to those reported by the nurses participating in this study, that is, that hospital routines were not postponed for skin-to-skin contact; thus, the newborns were taken to the warm crib for the first care before being placed on the mothers' lap $^{(3)}$.

As for the barrier to early SSC after birth, the nurses especially pointed out medical resistance. There is an opportunity for improvement in the practice of skin-to-skin contact based on the involvement of all the professionals who assist birth since, according to the reports below, some barriers have been identified in this regard:

[...] sometimes, the anesthesiologist says something like: "Oh, it's not possible, because I have to check the patient's pressure, I have to whatever..." [...] Sometimes, some other obstetrician comes and goes like: "Oh, it's hindering my workhere". (E1)

\section{[...] But the worst of all is the issue of the pediatrician, who is the one who really goes there and takes the baby from the mother. [...] There is very strong resistance by the medical team [...] they need to follow the hospital's rules... (E4) \\ [...] the doctors are in a hurry; the pediatrician is in a hurry to clamp the cord and remove the baby to examine [...] I think that Obstetrics and Pediatrics don't value that hour. (E7)}

The work of the professionals in the multidisciplinary team, such as biologists and interventionists, was highlighted in a study that shows that the hospital routine overlaps with humanized care and prevents the performance of SSC between mothers and newborns. Difficulties with the health team were exemplified, as in the case of obstetricians who ask to turn on the air conditioning and complain that the infant reduced their space to work; of anesthesiologists who complain that the newborns get in the way by being there with their mothers; of nursing technicians who say that their work increases, as they also need to take care of the newborns in the delivery room; and of pediatricians who think they must perform the exam immediately ${ }^{(7)}$.

The nurses mentioned other limiting factors for the practice of early SSC, such as environmental factors, demand for care and birth by cesarean section: 
[...] resistant team, in this sense, like... Sometimes, the pediatrician wants to remove them to be able to evaluate; sometimes, it's the anesthesiologist who wants to remove the baby... There, sometimes, the temperature of the room is not adequate. (E2)

[...] Of course, in some situations we get overwhelmed, we end up working, for example, we have a vaginal delivery and a C-section at the same time. I can't be in the two places at the same time [...] And, in the C-sections, we have an obstacle, which is sometimes the doctor's elbow over the mother's chest. [...] but there's also the air-conditioning issue, right? [...] Many situations, because the mothers, during the C-sections, are more likely to be sick, thus, they become more nauseated, sometimes, their arms are numb. They don't feel so safe to stay skin-to-skin, as the mothers who do vaginal delivery, right? (E4)

These reports indicate that the cesarean section limits the practice of SSC not only due to the biological effects of the surgery, but also to the professionals involved in the procedure. Corroborating the nurses'report, a study carried out in Paraná found that the professionals who assist parturients and newborns pointed to work overload and birth by cesarean section as challenges for the implementation of breastfeeding in the delivery room ${ }^{(14)}$.

These barriers to SSC at births by cesarean section were also identified in interviews with American nurses. They pointed out the insufficient number of professionals in the operating room, the low temperature of the room, the lack of knowledge of the professionals involved, work flow, lack of collaboration from the professionals, lack of space on the mother's chest, space dispute with the anesthesiologist, lack of protocols, and the need for a professional who is responsible for the practice in order to provide safety for the newborns ${ }^{(5)}$.

In the same context, the difficulty in performing SCC in cesarean sections stands out, as reported by E6, who prefers to wrap the newborns in Swaddling-cloth when placing them together with their mothers. The report showed insecurity for not being able to accompany the mothers and the newborns in the first hour after birth:

[...] it should be a little more adapted in the cesarean section, so that we can feel confident to place them [...] we can't stay there with the patient for one hour,20, 30 minutes, so, I leave skin-to-skin - I leave skin-to-skin, no, I wrap the baby. (E6)
A number of studies show that the cesarean section negatively interferes with SSC and breastfeeding, contributing to mother-baby separation. It can be said that compliance with this practice is intertwined with the delivery care model and that the type of delivery is decisive in the percentage of SSC and in the success of breastfeeding in the first hour of life ${ }^{(7,14)}$.

In order to mitigate the barriers to early SSC after cesarean sections, a study developed a proposal for safe action, which collaborates with the humanization requirements at birth. Countless strategies were implemented, such as: creation of a multidisciplinary committee to elaborate a protocol related to the practice of SSC after cesarean sections; encouragement of the presence of the companion; space for placing the newborn on the mother's lap and covering it with warm and dry cloths; warmer room temperature; repositioning of the electrodes placed on the mother; a professional responsible for ensuring safety of the newborn during this moment; training of the professionals involved; and more attention from the anesthesiologist, so as to prevent maternal symptoms that may impair this contact ${ }^{(15)}$.

In this way, the cesarean section does not need to be an impediment to the practice, since environmental factors can be modified by a sensitized and properly trained team. The multidisciplinary team plays a relevant role in assisting birth, being responsible for encouraging that humanized practices with scientifically proven benefits are implemented, avoiding the separation of mothers and newborns ${ }^{(4-16)}$. In this sense, nurses stand out as professionals capable of facilitating the practice of SSC ${ }^{(16)}$.

In this study, when asked about the facilitating factors for performing SSC in the hospital where they work, the nurses addressed the importance of the role played by the Nursing team, in particular, about the presence of the nurse in the delivery room and communication among the health teams:

\section{[...] I think, basically, this autonomy that nurses have to} introduce this topic, to come and say [...] this thing of talking to the obstetrician and the anesthesiologist. This is the facilitator. (E1)

[...] also the presence of the nurses in the delivery room, both in the delivery room and the cesarean room, but the moment, this facilitates this practice, because we encourage this early contact between them, right? Because we know when the baby is able to be close to the mother. (E3)

[...] I think what contributes is the nurse's willingness to do skin-to-skin. [...] If we don't value it, it doesn't happen. (E7) 
[...] Well, first we see that the Nursing team is well engaged. (E8)

It was observed in the statements that the work of the Nursing team and of the nurses as facilitating professionals for the SSC was valued. Corroborating this finding, a study carried out in a municipal maternity hospital in the city of Rio de Janeiro showed that, in births assisted by obstetric nurses, good practices in labor and birth are implemented, such as stimulating the presence of a companion, SSC and breastfeeding in the first hour of life ${ }^{(17)}$.

Other facilitating factors reported by the nurses were the presence of a companion, the use of institutional protocols, the current public policies, and the importance of women being well informed with respect to good practices at birth, as shown in the following statements:

[...] something specifically that favors here at the hospital, I think it would be the policies to which the hospital adhered, the public policies of the Ministry, which would be the Stork network, the Baby Friendly Hospital... (E4)

[...] many already know what skin-to-skin contact is, and this is very cool. They ask if they will be with the baby, many ask if they will spend an hour with the baby. (E5)

[...] an institutional indicator, so this is a good thing, it makes it easier for the baby to go. [...] The question of the presence of a companion also helps a lot, it facilitates. Us guiding the woman helps too; the hospital being child-friendly too... (E8)

Similar results were found in another study, in which professionals from the multidisciplinary health team indicated facilitators for SSC, such as: policies for comprehensive care for women and newborns, implementation of humanization practices in labor and birth recommended by governmental agencies, training and qualifications by means of continuing education in the hospital environment, parturient's autonomy and presence of a companion ${ }^{(7)}$. It is noteworthy that, during the interviews, the participants in this study pointed out that the medical team should participate more in institutional training on good practices at birth, as in the following report:

[...] in most trainings, when they happen, the entire Nursing staff attends, and the medical team doesn't, you know? [...] there should be a call for them too, for them to come and see how important it is [...] (E5)

The nurses believe that the training of the medical team is necessary to improve the practice of SSC. The reports reinforce that there are further training courses in the institution in which the Nursing team participates; however, it seems fundamental that other professional categories that work in the birth scenario participate in the training provided by the institution.

\section{Nursing records on skin-to-skin contact}

When asked about what they consider fundamental in the Nursing record related to the practice of SSC, the nurses expressed their opinions in few details, but highlighting the importance of the record:

\section{[...] That the record shows whether skin-to-skin was made ornot, and justify why it wasn't done [...] as it is a practice proved beneficial. (E2)}

[...] We record whether the baby made skin-to-skin contact, whether it didn't and why it didn't... We record whether the baby was fed in the first hour... (E4)

Nursing records are legal instruments that have several functions in the care context, such as providing information related to the care provided, ensuring communication between members of the health team, ensuring continuity of the information and enabling care planning. The records are part of the Systematization of Nursing Care and can serve as a data source for audits, research, teaching and legal processes, being considered an important tool for evaluating clients and the care provided ${ }^{(18)}$.

It is pointed out that Nursing records represent one of the most deficient fields of the Nursing Process in Brazil. Even though nurses understand their importance, there are several limitations to the proper record. Some limitations mentioned are insufficient human resources, work overload, lack of time for detailed record of the care provided, and lack of continuing education in the workplace ${ }^{(19)}$.

Regarding the record of SSC, a recurrent pattern was identified in the participants'reports regarding the use of the institutional printout of the record of good practices existing in the institution, referred in the sector as the "pink sheet", as an important instrument of record of SSC and breastfeeding in the first hour of life, as shown in the following statement:

[...] We have one, a sheet, which is the filling we have from skin-to-skin contact, which was very well assembled, and I like itvery much. I think that that is also a form of record, it's a pity that this sheet doesn't remain in the chart. (E7)

The importance of recording SSC and the practicality of the instrument already existing at the institution were emphasized. The nurse demonstrated that she knows that the 
record is a means of valuing the Nursing practice, expressed by the desire to identify the professional who performed the care and by the desire that this form be filed together with the other documents of the women:

\section{[...] It is filled just for research, I think it should be on the chart. It should be recorded there with the name; and the nurse who fills it should sign it, because I think skin- to-skin contact will only really happen and be enforced when the nurse takes on this role. (E7)}

In compliance with the nurse's statement, the Federal Nursing Council (Conselho Federal de Enfermagem, COFEN) Nursing Record Recommendations Guide indicates that, as a legal document, records will only be valid if they are dated and signed and, of course, if they are legible and have no erasures ${ }^{(9)}$. By analyzing the content of the Nursing notes in the medical records of hospitalized children, a study indicated lack of registration of names, categories, professional registration number and signature of the person who took the notes, making it difficult or impossible for them to be legal and audited ${ }^{(18)}$.

In contrast to the previous statement, one participant does not agree with the SSC Nursing records being written on paper forms, as can be seen in the following statement:

\section{[...] I think it should be recorded in the progress chart, because in the progress chart it remains recorded. In leaflets, the sheets disappear. (E1)}

In the institution under study, the Nursing progress chart is recorded in electronic medical records, with little information in the paper medical records. The Nursing progress chart is characterized as one of the most critical stages of the Nursing Process, as it supports the applicability of the work, defining whether the previous care stages were effective, observing new needs and enabling solutions for them. Through the Nursing Process, the nurses identify the needs of those under their care, improve quality of care and promote the scientific development of Nursing ${ }^{(20)}$.

The nurses made few suggestions. As for the record of SSC in an institutional form, they seem to be satisfied with the instrument for the record already existing at the institution. Regarding the content of the records, a nurse stressed that it is important to record the woman's perception about SSC:

[...] how it is for the mother, her perception of skin-toskin contact, because, just as there are mothers that you place the baby there and they love it, like it, there are mothers who ask to remove the baby, right? So, I think that the mother's perception is paramount in the Nursing record... (E8)

The COFEN Nursing Record Recommendations Guide does not provide records related to patients' emotions and feelings in the immediate postpartum period ${ }^{(9)}$. However, it is up to the nurse, through the Nursing Process, to establish a communication flow between the patient and the health team, making records that reflect care in a clear and reliable manner.

\section{FINAL CONSIDERATIONS}

The nurses'knowledge about early SSC suggests willingness to implement scientific evidence on good practices at birth in the care practice. The nurses' reports instruct that SSC should be performed in the recommended manner; however, the limitations related to the health team's work processes are highlighted. They see the importance of this contact for mothers and newborns and relate the practice to humanized care at birth.

In addition, from the perspective of the obstetric nurses interviewed, SSC happens partially in their workplace, since the newborns do not stay with their mothers immediately after delivery for an hour and without interruption. The participants see themselves as facilitators for SSC, but they need to overcome daily challenges of the work routine to achieve it.

Regarding the Nursing records on the practice, the nurses understand their importance, but they seem to be satisfied with the way in which the record is made, not enriching the practice performed in details. The perception about fundamental aspects of the practice record seems to be summarized in: the baby was placed in SSC, yes or no, and why not.

The limitations of this study refer to the fact that the research was carried out in a specific health service, and that it did not include other locations with a similar care proposal. Furthermore, qualitative research is influenced by the participants'perceptions and experiences, which does not exhaust the theme. Future research studies with a qualitative approach are suggested to deepen and explore the opinion of professionals and women about the experiences of early SSC and its records.

This study reinforces the importance of shifting paradigms regarding the hospital-centered culture of care in delivery and birth. The practice of SSC seems to be making progress over the years, but there are still opportunities for improvement. It is necessary that the multidisciplinary health team is updated on the scientific evidence to ensure better care 
at birth, avoiding unnecessary interventions and bringing mothers and newborns closer and closer.

\section{DEFERENCES}

1. Braga TL, Santos SCC. Parto humanizado sob a ótica da equipe de enfermagem do Hospital da Mulher Mãe Luzia. Rev Eletrôn Estácio Saúde. 2017 [cited 2018 Jun 22];6(1):20-33. Available from: http://revistaadmmade.estacio.br/index. php/saudesantacatarina/article/viewFile/3641/1563

2. World Health Organization (CH).WHO recommendations: intrapartum care for a positive childbirth experience. Geneva:WH0; 2018 [cited 2019 Jul 10]. Available from: https://apps.who.int/iris/bitstream/handle/10665/260178/9789241550215-eng. pdf? sequence $=1$

3. Koopman I, Callaghan-Koru JA, Alaofin O, Argani CH, Farzin A. Early skin-to-skin contact for healthy full-term infants after vaginal and caesarean delivery: a qualitative study on clinician perspectives. J Clin Nurs. 2016;25(9-10):1367-76. doi: https://doi.org/10.1111/jocn.13227

4. Abdala $L G$, Cunha MLC. Contato pele a pele entre mãe e recém-nascido e amamentação na primeira hora de vida. Clin Biomed Res. 2018;38(4):356-60. doi: https://doi.org/10.4322/2357-9730.82178

5. Balatero JS, Spilker AF, McNiesh SG. Barriers to skin-to-skin contact after cesarean birth. MCN Am J Matern Child Nurs. 2019;44(3):137-43. doi: https:// doi.org/10.1097/NMC.0000000000000521

6. Fundo das Nações Unidas para a Infância (BR). Iniciativa Hospital Amigo da Criança: revista, atualizada e ampliada para 0 cuidado integrado. Módulo 1 histórico e implementação [Internet] Brasília, DF: Ministério da Saúde;2008 [cited 2018 Jun 20]. Available from: http://www.redeblh.fiocruz.br/media/ modul01_ihac_alta.pdf

7. Kologeski TK, Strapasson MR, Schneider V, Renosto JM. Skin to skin contact of the newborn with its mother in the perspective of the multiprofessional team. Rev Enferm UFPE On line. 2017 [cited 2019 Jul 10];11(1):94-101. Available from: https://periodicos.ufpe.br/revistas/revistaenfermagem/article/view/11882/14340

8. Vittner D, Cong X, Ludington-Hoe SM, MCGrath JM. A survey of skin-to-skin contact with perinatal nurses. Appl Nurs Res. 2017;(33):19-23. doi: https://doi. org/10.1016/j.apnr.2016.09.006

9. Conselho Federal de Enfermagem (BR). Guia de Recomendações para Registro de Enfermagem no Prontuário do Paciente e outros documentos de Enfermagem. Brasília, DF; 2015 [cited 2018 Jun 18]. Available from: http://www.cofen.gov. br/wp-content/uploads/2016/08/Guia-de-Recomenda\%C3\%A7\%C3\%B5esCTLN-Vers\%C3\%A30-Web.pdf
10. Minayo MCS. 0 desafio do conhecimento: pesquisa qualitativa em saúde. 13. ed. São Paulo: Hucitec; 2013.

11. Minayo MCS, Deslandes SF, Gomes R. Pesquisa social: teoria, método e criatividade. 18. ed. Petrópolis: Vozes; 2011.

12. Ministério da Saúde (BR). Conselho Nacional de Saúde. Resolução 466, de 12 de dezembro de 2012. Dispõe sobre as diretrizes e normas regulamentadoras de pesquisa envolvendo seres humanos [Internet]. Brasilia, DF; 2012 [cited 2018 Jun 20]. Available from: http://bvsms.saude.gov.br/bvs/saudelegis/cns/2013/ res0466_12_12_2012.html

13. Brimdyr K, Cadwell K, Stevens J, Takahashi Y. An implementation algorithm to improve skin-to-skin practice in the first hour after birth. Matern Child Nutr. 2018;14(2):e12571. doi: https://doi.org/10.1111/mcn.12571

14. Antunes MB, Demitto MO, Soares LG, Radovanovic CAT, Higarashi IH, Ichisato SMT, et al. Amamentação na primeira hora de vida: conhecimento e prática da equipe multiprofissional. Av Enferm. 2017;35(1):19-29. doi: https://doi.org/10.15446/ av.enferm.v35n1.43682

15. Romero MC, Mallada PL, Gómez NMD. Contacto piel com piel tras um parto cesárea: puesta al día y propuesta de actuación. Rev Esp Salud Publica. 2019 [cited 2020 0ct 10];93:e1-10. Available from: http://scielo.isciii.es/pdf/resp/ v93/1135-5727-resp-93-e201902006.pdf

16. Farias RV, Souza ZCSN, Morais AC. Prática de cuidados imediatos ao recém-nascido: uma revisão integrativa de literatura. Rev Eletrôn Acervo Saúde. 2020;56:e-3983. doi: https://doi.org/10.25248/reas.e3983.2020

17. Ramos WMA, Aguiar BGC, Conrad D, Pinto CB, Mussumeci PA. Contribution of obstetric nurse in good practices of childbirth and birth assistance. Rev Pesqui Cuid Fundam. 2018;10(1):173-9. doi: https://doi.org/10.9789/2175-5361.2018. v10i1.173-179

18. Caldeira MM, Souza TV, Morais RCM, Moraes JRMM, Nascimento LCN, Oliveira ICS. Annotations of the nursing team: the (dis) appreciation of care for the information provided. Rev Pesqui Cuid Fundam. 2019 [cited 2020 Jul 10];11(1):135-41. Available from: http://www.seer.unirio.br/index.php/cuidadofundamental/ article/view/6534/pdf

19. Figueiredo T, Silva PLN, Guimarães LF, Guimarães CF, Oliveira MKS, Alves ECS. Assessment of nursing records of patients admitted to the medical clinic of a university hospital from the northern region of Minas Gerais State. Rev Pesqui Cuid Fundam. 2019;11(2):390-6. doi: https://doi.org/10.9789/2175-5361.2019. v11i2.390-396

20. Silva TG, Silva GA, Moser DC, Maier SRO, Barbosa LC. Nursing care systematization: the nurses'perception. Rev Pesq Cuid Fundam. 2018;10(4):998-1007. doi:https:// doi.org/10.9789/2175-5361.2018.v10i4.998-1007 


\section{- Authorship contribution:}

Jéssica Strube Holztrattner - Conceptualization; Data curation; Formal analysis; Investigation; Methodology; Resources; Software; Supervision; Validation;

Visualization; Writing - Original draft preparation;

Writing - Review and editing.

Helga Geremias Gouveia - Conceptualization; Data curation; Formal analysis; Investigation; Methodology; Supervision; Validation; Visualization; Writing - Original draft preparation; Writing - Review and editing.

Marianna Goes Moraes - Investigation; Methodology; Visualization; Writing - Original draft preparation;

Writing - Review and editing.

Franciela Delazeri Carlotto - Investigation;

Methodology; Visualization; Writing - Original draft preparation; Writing - Review and editing.

Bruna Euzébio Klein - Investigation; Methodology;

Visualization; Writing - Original draft preparation;

Writing - Review and editing.

Débora Fernandes Coelho - Conceptualization; Data curation; Formal analysis; Investigation; Methodology; Supervision; Validation; Visualization; Writing - Original draft preparation; Writing - Review and editing.

\section{- Corresponding author:}

Jéssica Strube Holztrattner

Email: jessica.holztrattner@gmail.com

Associate editor:

Jéssica Machado Teles

Editor-in-chief:

Maria da Graça Oliveira Crossetti 